\title{
Rubber Material Properties of Several Rubber Tree Strains
}

\author{
Wang Kaidian ${ }^{1}$, Han Quanhui ${ }^{1}$,Lu qingzhi ${ }^{1}$, Chen Zhanxiong ${ }^{1}$,Li Jianhui ${ }^{1}$ and Yao Xingcheng ${ }^{2 *}$ \\ ${ }^{1}$ Chinese Academy of Tropical Agricultural Sciences proving ground, Danzhou, 571737, china \\ ${ }^{2}$ Rubber Research Institute, Chinese Academy of Tropical Agricultural Sciences, Haikou, 571101, china
}

\begin{abstract}
The rubber from rubber tree strain reyan 8-79 (hainan), zhanshi 218-6 (guangdong), yunyan 73-46 and yunyan 75-11 (yunnan) were tested to determine the physical and chemical properties, processing properties of raw rubber and physical and mechanical properties of vulcanized rubber. The results showed that raw rubber from different tree strains had different physical and chemical properties, processing properties,and the physical and mechanical properties of vulcanized rubber were different as well. Yunyan 75-11 had the highest mooney viscosity, Reyan 8-79 had the highest protein content, Zhanshi 218-6 had the best tensile and tearing strength, Yunyan 73-46 had small elastic modulus, large loss factor and good processing properties.
\end{abstract}

\section{Introduction}

Natural rubber is made of rubber latex secreted by the artificial cultivated rubber tree through solidification, drying and processing ${ }^{[1-2]}$. Natural rubber is a kind of natural, macromolecular, biosynthetic compounds, and the chemical composition of latex is influenced by rubber tree strain, age, soil, climate and tapping system ${ }^{[3-7]}$. The chemical composition of latex has influence on the performance of the latex, while latex products are mainly composed of mixed latex, so its performance is mainly affected by the strain of natural rubber in use.

Past researches.have shown that fresh latex, revertex rubber, raw rubber and vulcanized rubber from different strains show different properties ${ }^{[8-13]}$. China's three major rubber planting areas, Hainan, Yunnan and Guangdong breeding strain varies due to climate differences, different strains of rubber have different performance. The raw rubber and vulcanized rubber of Yunnan rubber planting area promotion strains (Yunyan 73-46 and 75-11), Hainan rubber planting area promotion strains (Reyan 8-79), Guangdong rubber planting area promotion strains (Zhanshi 218-6) are studied, in order to understand the properties and processing properties of different strains natural rubber, further to provide theoretical basis for selection of high quality natural rubber materials when processing natural rubber latex products.

\section{Materials and methods}

\section{1. material}

Materials: $10 \mathrm{~kg}$ Natural rubber latex of Reyan 8-79 from Danzhou, Hainan (Chinese academy of tropical agriculture test rubber factory), $10 \mathrm{~kg}$ Natural rubber latex of Yunyan $73-46$ and $10 \mathrm{~kg}$ Natural rubber latex of Yunyan 75-11 from Basa farm of Hekou, Yunnan, 10kg Natural rubber latex of Zhanshi 218-6 from new era farm of Huazhou, Guangdong.

\subsection{Preparation of raw rubber}

$10 \mathrm{~kg}$ Natural rubber latex, added 2\% acetic acid, fully mixed, let it on stand, granulated when latex coagulation, dried in oven with the constant temperature of $70{ }^{\circ} \mathrm{C}$, brought it out when the glue sample with pale yellow appearance and without white spots.

\subsection{Preparation of vulcanized rubber}

Recipe: raw rubber, 100, Zinc Oxide 6.00, Sulfur 3.50, Stearic Acid 0.50, 2-Mercaptobenzothiazole (MBT) 0.50 .

Rubber compound: take raw rubber sample, plasticizing and mixing in the open rubber mixing machine, added the chelating agent as conventional mixing process.

Vulcanized rubber: Place Rubber compound for $6 \mathrm{~h}$ to measure the curing time. The curing condition is $140^{\circ} \mathrm{C}$, $30 \mathrm{~min}$. According to the measured curing time, the sample was vulcanized on the plate vulcanizing machine, and then cooled down with cool water to obtain vulcanized rubber ${ }^{[14]}$.

\subsection{Determination of rubber properties}

According to the national standards for determination of raw rubber performance. Mooney viscosity according to GB/T 1232.1-2000; $\mathrm{P}_{0}$ according to GB/T3510-2006; PRI according to GB/T3517-2002; Nitrogen content according to GB/T8088-2008; Constant stress, breaking elongation and tensile strength according to 
GB/T528-1999; Tear strength according to GB/T 529-1999; Shore A hardness according to $\mathrm{GB} / \mathrm{T}$ 531-1999.

\subsection{Testing on rubber processing analyzer}

Testing was performed on rubber processing analyzer (RPA2000) to determine shear modulus and loss factor. Conditions of temperature scanning: scanning frequency $1.67 \mathrm{~Hz}$, strain $6.98 \%$. Conditions of strain scanning: scanning temperature $100^{\circ} \mathrm{C}$, frequency $0.1 \mathrm{~Hz}$. Conditions of frequency scanning: scanning temperature $100^{\circ} \mathrm{C}$, strain $6.98 \%$.

\section{Result and analysis}

\subsection{Properties of natural raw rubber}

Properties of natural raw rubber of different strains are shown in table 1. The strain Yunyan 75-11 has the highest Mooney viscosity and Wallace plastic initial value (P0), the strain Zhanshi 218-6 cultivated in Guangdong has lower Mooney viscosity and Wallace plastic initial value (P0) than others. That is to say Mooney viscosity and Wallace plastic initial value are positive correlation. The strain Yunyan 73-46 cultivated in Yunnan has higher plastic retention (PRI) and good performance in aging resistance to heat and oxygen. The strain Reyan 8-79 cultivated in Hainan has higher nitrogen content, so do the protein content.

Table1 . Properties of different strain natural raw rubber

\begin{tabular}{ccccc}
\hline Strain & Mooney Viscosity $\left[\mathrm{ML}(1+4) 100^{\circ}\right]$ & $\mathrm{P}_{0}$ & PRI/\% & nitrogen content $/ \%$ \\
\hline Zhanshi 218-6 & 58 & 30 & 70 & 0.45 \\
Reyan 8-79 & 67 & 34 & 66 & 0.61 \\
Yunyan 73-46 & 59 & 33 & 74 & 0.34 \\
Yunyan 75-11 & 74 & 40 & 64 & 0.34 \\
\hline
\end{tabular}

\subsection{Physical and mechanical properties of vulcanized rubber}

As shown in table 2 below, the strain Zhanshi 218-6cultivated in Guangdong has the highest tensile and tearing strength, while the strain Reken 628 cultivated in Hainan has the lowest tensile and tearing strength, but
Reyan 8-79 has the highest breaking elongation, Zhanshi 218-6 cultivated in Guangdong has the lowest breaking elongation. the strain Zhanshi 218-6 cultivated in Guangdong has the highest Shore A hardness. It shows the greater the tensile strength is, the greater the Shore A hardness is.

Table2. Physical and mechanical properties of different vulcanized rubber

\begin{tabular}{ccccccc}
\hline Strain & $\begin{array}{c}\text { Tensile strength } \\
\text { /MPa }\end{array}$ & $\begin{array}{c}\text { Tear strength / } \\
\left(\mathrm{KN} \cdot \mathrm{m}^{-1}\right)\end{array}$ & $\begin{array}{c}300 \% \text { Tensile } \\
\text { Stress } / \mathrm{MPa}\end{array}$ & $\begin{array}{c}500 \% \text { Tensile } \\
\text { Stress /MPa }\end{array}$ & $\begin{array}{c}\text { Elongation } \\
\text { at break } / \%\end{array}$ & Shore A \\
\hline Zhanshi 218-6 & 27 & 30 & 1.52 & 2.92 & 861 & 39 \\
Reyan 8-79 & 20 & 25 & 1.20 & 2.01 & 951 & 34 \\
Yunyan 73-46 & 23 & 27 & 1.35 & 2.59 & 899 & 37 \\
Yunyan 75-11 & 23 & 29 & 1.33 & 2.52 & 922 & 38 \\
\hline
\end{tabular}

\subsection{Processing properties of natural raw rubber}

\subsubsection{Temperature scanning}

The result of temperature scanning performed on rubber processing analyzer is shown in Figure 1 and Figure 2. The strain Reyan 8-79 cultivated in Hainan has the largest elastic modulus $G^{\prime}$ and the minimum loss factor. The strain Yunyan 73-46 cultivated in Yunnan has smaller elastic modulus, larger loss factor and good processing properties. Strains in different areas have different elastic modulus and loss factor, therefore, the molecular weight and molecular weight distribution of the strain Reyan 8-79 cultivated in Hainan, the strain Yunyan 73-46, Yunyan 75-11 cultivated in Yunnan and the strain Zhanshi 218-6 cultivated in Guangdong are different, the processing properties are also different.

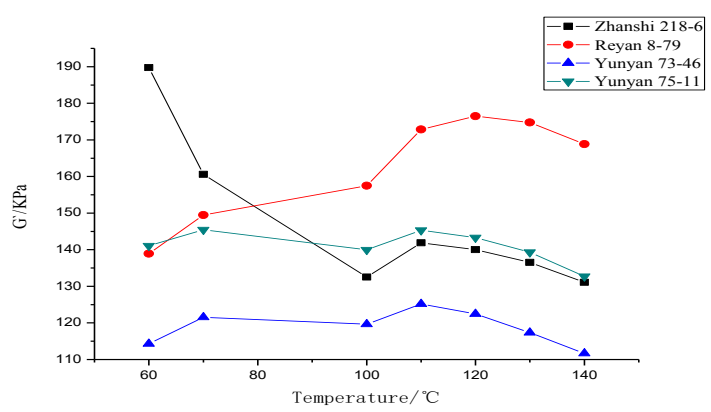

Figure 1. Response of elastic modulus of natural raw rubber to temperature in different areas 


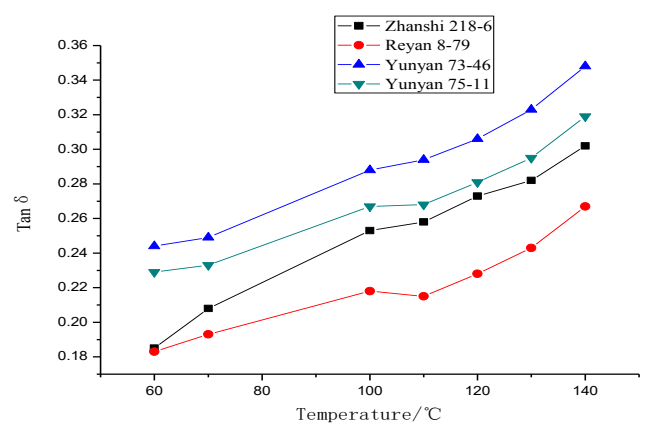

Figure 2. Response of loss factors of natural raw rubber to temperature in different areas

\subsubsection{Strain scanning}

The result of strain scanning performed on rubber processing analyzer is shown in Figure 3. With the increase of strain, the elastic modulus $G^{\prime}$ in various areas tends to be stable. The strain Reyan 8-79 cultivated in Hainan has the largest elastic modulus $G^{\prime}$. The strain Yunyan 73-46 cultivated in Yunnan has smaller elastic modulus. The strain Yunyan 75-11 and Zhanshi 218-6 are almost on the same level. The larger elastic modulus $\mathrm{G}^{\prime}$ is, the greater is the mouth expansion rate, and the worse is the product stability.

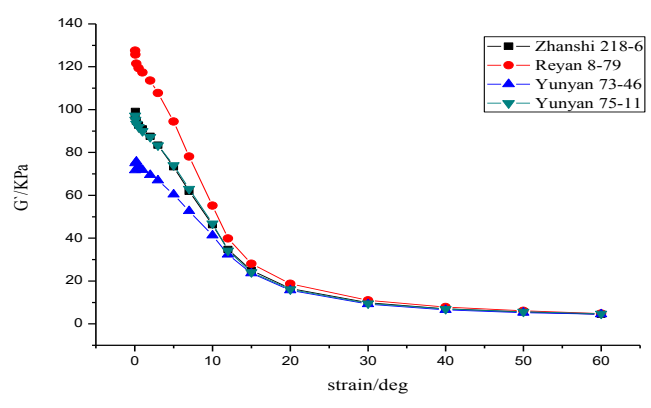

Figure 3. Response of elastic modulus of natural raw rubber to strain in different areas

\subsubsection{Frequency scanning}

The result of frequency scanning performed on rubber processing analyzer is shown in Figure 4 and 5 . The strain Reyan8-79 cultivated in Hainan has the largest elastic modulus. The strain Yunyan 73-46 cultivated in Yunnan has smallest elastic modulus. The strain Reyan 8-79 has the smallest loss factor, the strain Yunyan 73-46 has the largest loss factor. The elastic modulus and loss factor of the strain Yunyan 75-11 and Zhanshi 218-6 are similar, indicating that they have similar molecular weight and molecular weight distribution. The loss factor is larger, so is the relative displacement between molecules and the internal friction, thus the molecular fluidity is better. The larger is the elastic modulus, the greater is the Mooney viscosity.

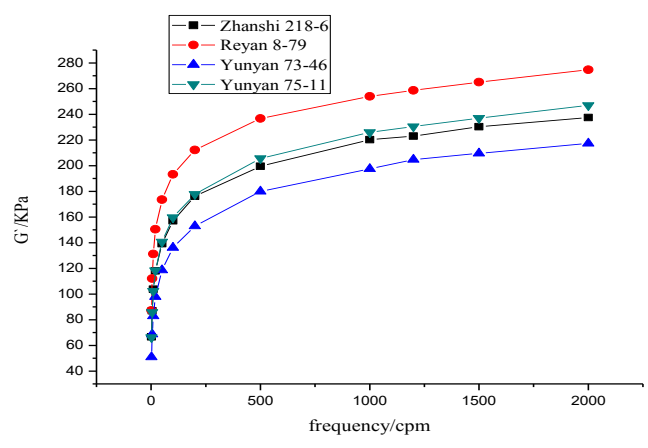

Figure 4. Response of elastic modulus of raw rubber to frequency in different areas

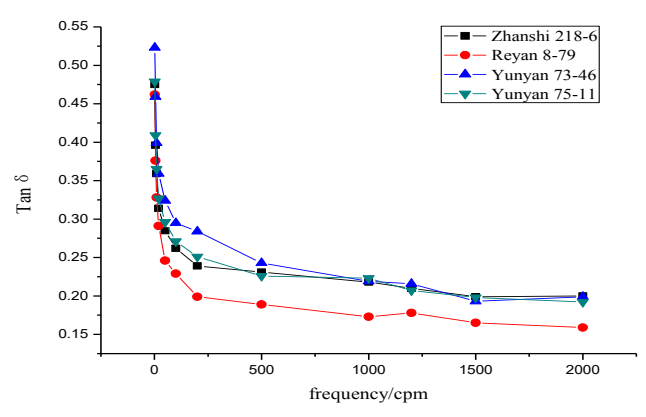

Figure 5. Response of loss factor of natural raw rubber to frequency in different areas

\section{Discussion and conclusion}

Natural rubber and rubber latex of different strains show varying degrees of difference in properties, such as particle size, molecular weight distribution, vulcanization characteristics of raw rubber, aging resistance of vulcanized rubber, etc ${ }^{[8-13]}$. In this study, the rubber properties of different strains in several rubber planting areas are also different. The strain Yunyan 75-11 has the highest Mooney viscosity and Wallace plastic initial value (P0), the strain Zhanshi 218-6 cultivated in Guangdong has lower Mooney viscosity and Wallace plastic initial value $\left(\mathrm{P}_{0}\right)$ than others. It shows that there is a positive correlation between Mooney viscosity and Wallace plastic initial value. The conclusion is consistent with the previous research. The strain Yunyan 73-46 cultivated in Yunnan has higher plastic retention (PRI) and good performance in aging resistance to heat and oxygen. The strain Reyan 8-79 cultivated in Hainan has higher nitrogen content, means it has higher protein content.

The shear modulus, loss factor of rubber materials measured by the rubber processing analyzer has a good correlation with the physical properties such as stress at definite elongation, rebound value and heat generation determined by conventional methods ${ }^{[15]}$. Therefore, rubber processing analyzer (RPA2000) was used in this study to test the viscoelasticity of rubber, further to determine the processing properties of rubber, vulcanization state and the use of rubber products. The results of the processing analyzer shows that the 
processing properties of natural raw rubber of different strains are different. The strain Reyan 8-79 cultivated in Hainan has the highest elastic modulus $G^{\prime}$ and the lowest loss factor. The strain Yunyan 73-46 cultivated in Yunnan has lower elastic modulus, higher loss factor and good processing performance. There is a negative correlation between elastic modulus and loss factor, which indicates that the test results are consistent with the theory. The elastic modulus and loss factor of strains in different areas are different, so the molecular weight, molecular weight distribution and the processing properties of Reyan 8-79, Yunyan 73-46 and 75-11, Zhanshi 218-6 are different.

\section{The following conclusions can be drawn in this study:}

(1) The properties and processing properties of raw rubber, physical and mechanical properties of vulcanized rubber are different in different areas. Zhanshi 218-6 vulcanized rubber has the largest tensile strength, tear strength and shore A hardness. Reyan 8-79 has the largest elongation at break and the highest nitrogen content. Yunyan 75-11 has the highest Wallace plastic initial value and Mooney viscosity.

(2) Yunyan 73-46 has good resistance against aging and oxygen and processing performance. Reyan 8-79 has poor processing performance and product stability. The molecular weight and weight distribution of Zhanshi 218-6 are similar to that of Yunyan 75-11.

\section{Acknowledgements:}

This research was financially supported by Fundamental Research Business Expenses of Public Welfare Research Institutions at the Central Level (Grant No. 1630092019014).

\section{Reference}

1. Y IP, E.(1990) Clonal characterization of latex and rubber properties. J. Journal of Natural Rubber Research, 5: 52- 80.

2. HAQUE,M. E. , AKHTAR F, DAFADER N. C. , A lSIDDIQUE F.R.(1995) Characterization of natural rubber latex concentrate from Bangladesh. J. Macromolecules Reports, 32: 435- 445.

3. Le R Y,Ehabe E,Sainte B J,et al. (2000)Seasonal and clonal variation in the latex and raw rubber of Hevea brasiliensis. J. Journal of Rubber Research, 3:142.

4. Ferreira M,Moreno R M B,Goncalves P de S,et al. (2002)Evaluation of natural rubber from clones of Hevea brasiliensis. J. Rubber Chemistry and Technology, 75:1.

5. Moreno R M B,Ferreira M,Goncalves $\mathrm{P}$ de S,et al.(2003)Avaliacao do latex eda borracha natural de clones de seringueira no Estado de Sao Paulo. J. Pesquisa Agropecuaria Brasileira, 38:583.

6. He Y P. (2007) Natural Rubber Processing. Hainan
Publishing House, Hainan:

7. Li P W. (2004)Effect of chemical stimulation tapping on properties of concentrated latex and its vulcanized latex film. Master's thesis of South China Tropical Agricultural University, (5):4-6.

8. Chen $\mathrm{X} \mathrm{G}$, Zhang $\mathrm{H} \mathrm{P}$, Zhang $\mathrm{Y} \mathrm{H}$, et al. (2007)Molecular properties and properties of new rubber varieties Yunyan 77-2 and Yunyan 77-4. J. Tropical Agricultural Science and Technology, 30(2).

9. Wu C, Liao X X, Liao S Q, et al. (2011)Composition and Gum-forming Properties of Different Strains of Rubber Trees . J. chinese agricultural science bulletin ,27(16):7-10

10. Chen H F, Zhang H P, Chen X G. (2008)Study on molecular weight, molecular weight distribution and properties of natural rubber. A. Tropical Agriculture in Guangxi, 3(116).

11. Zeng Z Q, Huang M F and Chen M. (2009)Study on Aging Resistance of Natural Rubber Vulcanizates of Different Strains. A. Material Report, (2):478-480.

12. Liao X X, Wu C, Liao S Q, et al. (2011) Study on the Properties of Natural Rubber Latex of Different Strains. J. Guangdong Chemical Industry, 38(3):45-46.

13. Wen X J, Liao X X, Liao S Q, et al. (2013)Structures and properties of two strains of natural rubber. J. Elastomer, 23(1):44 47 .

14. Li Z J. (2007)Analysis and test of natural rubber. China Agricultural University Press, Beijing, (6):2-242.

15. Gregory M J ,(1975)Tan S N .some observations on storage hardening of natural rubber, Proceed-ings of International Rubber Conference, Kuala Lumpur, 428. 